\title{
Large Scale Fire Tests: the British Steel European Collaborative Research Programme on the BRE 8- Storey Frame
}

\author{
B.R. KIRBY \\ British Steel PLC. \\ Swinden Technology Centre \\ Moorgate, Rotherham, S60 3AR, England, UK
}

\begin{abstract}
During the last two years a major European fire research programme has been carried out on the BRE 8-storey frame built within the large scale test facility at Cardington in the UK. This paper describes the background to the work, the tests carried out, some of the results and how these are increasing our understanding of the behaviour of real structures in fire. It also describes how notable features of the structural behaviour which occurred during the fire tests, are identifying issues that need to be addressed both in design and further research aimed at the development of fire safety engineering.
\end{abstract}

Keywords: Steel, Structures, Natural fires, ISO834,

\section{INTRODUCTION}

As part of developing the relatively new discipline of fire safety engineering into Codes encompassing all aspects of designing safe buildings, it is essential that the behaviour of structural frameworks are thoroughly understood. In this way, we can not only quantify and design for some of the beneficial effects in building performance that are known to exist such as; continuity, restraint and load redistribution as seen in recent fires but more importantly, identify limitations and deficiencies that need to be addressed which otherwise would not be apparent by evaluating and designing elements in isolation.

It is also recognised that in following the prescriptive systems while the same level of fire resistance is usually specified for all the stuctural components within a compartment or building, in reality, their safety margins may be quite different. By studying the behaviour of complete frames, a greater emphasis can be placed upon identifying and improving upon the weakest link. 
During the last two years British Steel Swinden Technology Centre has been leading a major European collaborative fire research programme jointly sponsored by the European Coal and Steel Community (ECSC) with TNO (The Netherlands) and CTICM (France) as partners. The aim of the project was to carry out a programme of fire tests on the 8-storey frame built within the Building Research Establishment (BRE) test facility at Cardington, with the overall objective of understanding and developing numerical analysis procedures for describing the behaviour of structural steel frameworks subject to fire attack. By quantifying the structural response when parts of the frame are heated, would enable design rules to be developed and lead to fire safety measures being applied more effectively and economically.

\section{BRE 8-STOREY FRAME}

The BRE frame was designed as a modern office building in accordance with the UK building codes, Figure 1. Although its purpose was for research, to ensure it was representative of modern day construction, it was built under normal commercial pressures.

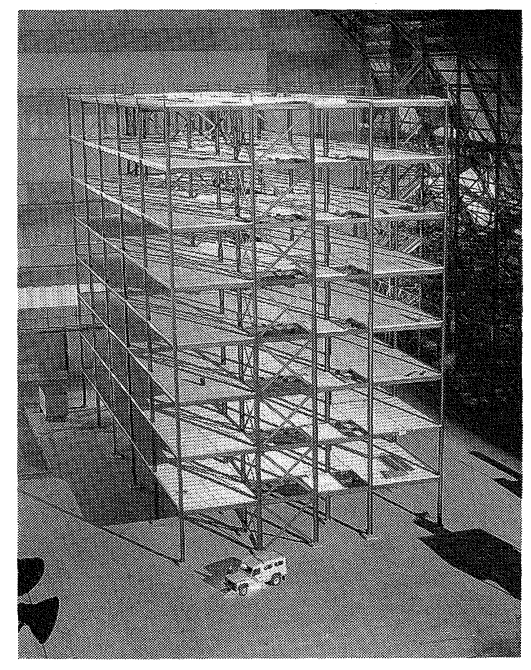

FIGURE 1. THE BRE 8-STOREY FRAME (STEELWORK ONLY) - Courtesy of BRE

The building is a modern, 8-storey composite design based upon a $6 \mathrm{~m}, 9 \mathrm{~m}, 6 \mathrm{~m}$ grid system which in plan has an area of $945 \mathrm{~m}^{2}$. The main beam to column connections are simple partial depth end plates with fin plates at the secondary beam connections. Composite action is achieved by shear studs welded through the steel decking onto the upper flanges of both the primary and secondary beams. The floor slab is lightweight concrete, $130 \mathrm{~mm}$ thick and incorporates an anti-cracking mesh. At the gable ends, blockwork walls are built full height with $0.9 \mathrm{~m}$ high dado walls along the sides at each level. 
Based upon surveys carried out by BRE of the service loadings found in typical office buildings, sand bags are uniformly distributed throughout the structure to provide full dead $+1 / 3$ live load as calculated according to the UK Codes.

\section{TEST PROGRAMME}

In the experimental programme four tests were planned, generically referred to as :
1D - Restrained Beam
2D - Plane Frame
3D - Corner
Office Fire (Demonstration)

The first three tests were designed to investigate different aspects of structural behaviour and therefore the heating regime was not important providing it could be controlled and achieve the desired temperatures. The results and lessons learnt were then applied by creating a real fire scenario in an office environment to provide a severe test to part of the structure.

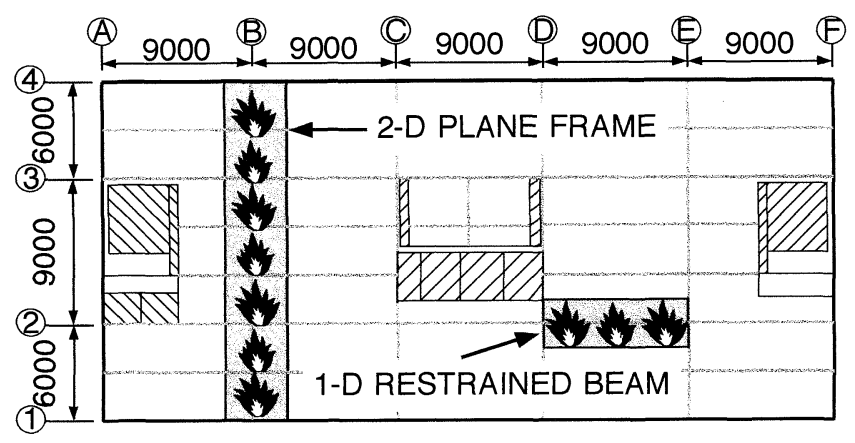

FIGURE 2. LOCATION OF TESTS 1 AND 2.

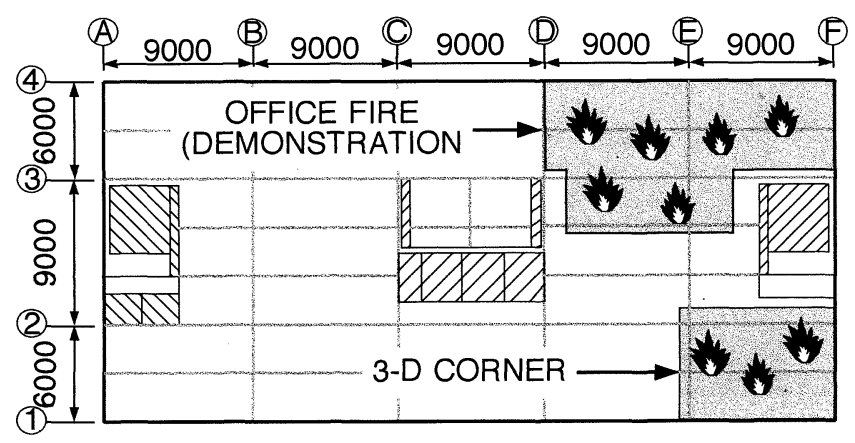

FIGURE 3. LOCATION OF TESTS 3 AND 4. 
In order to achieve the objectives of the programme, it was necessary to determine the ability of the frame to provide alternative load paths when one or more members loses its strength and stiffness. For this reason, parts of the structure were permitted to deform and deflect considerably further than would normally be considered acceptable in an ISO834 fire test. By adopting this approach, some aspects of structural behaviour rarely seen in a controlled environment, would otherwise not have been observed and monitored.

Throughout the programme the test areas and surrounding frame were extensively instrumented to measure changes to both physical and engineering parameters. Up to 600 separate pieces of instrumentation were installed for each test.

\section{D - Restrained Beam}

It is known that floor beams in structures which are designed as simply supported will be provided with some degree of restraint and continuity at the connections. This has been demonstrated from investigation of both real fires and ISO834 fire resistance tests on stub column beam connections conducted by British Steel. However, in composite construction much of the restraint and continuity is provided by the composite slab. Since this spans in two directions it would be difficult to evaluate in the Standard test furnace.

The first test was carried out on the seventh floor of the building in which a furnace was designed to heat a $305 \times 165 \mathrm{~mm}$ beam and the surrounding slab spanning $9 \mathrm{~m}$ between a pair of $254 \times 254$ column sections. It was also necessary to keep the connections as near as possible at ambient temperature. In view of the importance of achieving a uniform temperature profile along the length of the beam, an $8 \mathrm{~m} \times 3 \mathrm{~m}$ wide gas fired furnace was built up to the underside of the floor slab, Figure 4.

The beam was heated between $3-10^{\circ} \mathrm{C} / \mathrm{min}$. until temperatures of $800-900^{\circ} \mathrm{C}$ were achieved through the section's profile. At this point the mid-span of the beam had deflected $230 \mathrm{~mm}$ (L/35). Normally with the same level of loading applied in the Standard test, the deflection

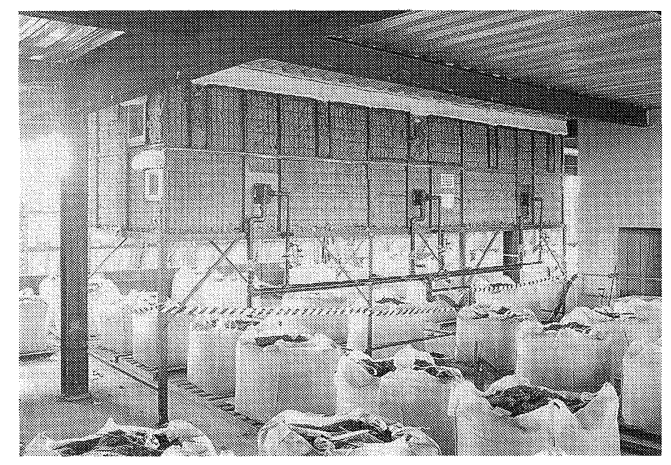

FIGURE 4. FURNACE ARRANGEMENT FOR HEATING THE RESTRAINED BEAM 


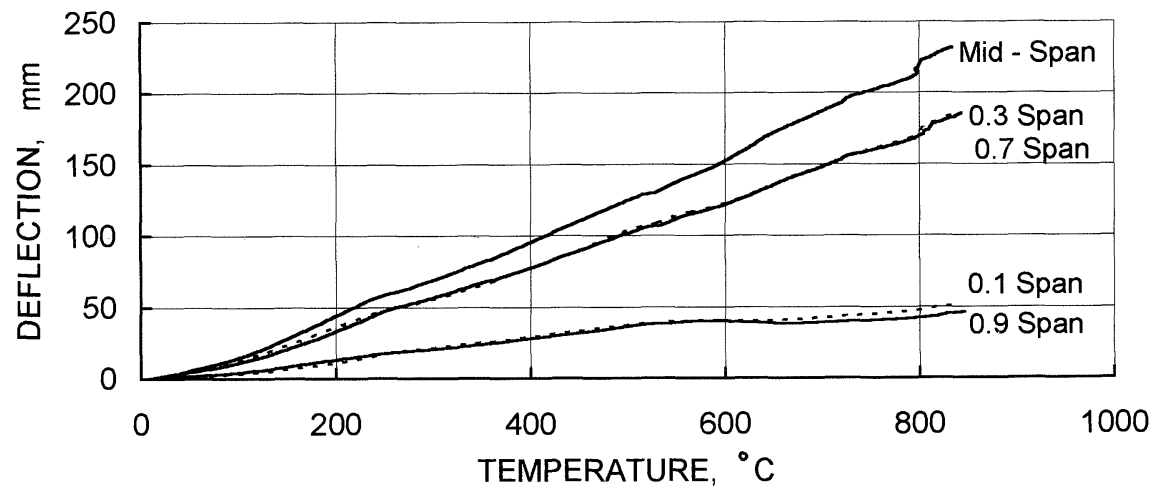

FIGURE 5. VERTICAL DEFLECTION VS LOWER FLANGE TEMPERATURE

limit $(\mathrm{L} / 30)$ would have been attained at a lower flange temperature of less than $700^{\circ} \mathrm{C}$. In Figure 5 , vertical deflection is shown as a function of lower flange temperature at several locations along the beam which illustrates that even when the test was terminated, 'runaway' (instability) had not been achieved.

The heating rate adopted was much slower in comparison to that experienced by unprotected steel and was more appropriate to insulated members exposed over a period of 1-2 hours. However, an essential feature of the test was to evaluate the role of the composite action and therefore it was necessary to examine the more detrimental effects of allowing time for heat to be conducted through the concrete to the reinforcement.

Figure 6 shows one end of the beam in which local buckling had occurred just inside the furnace. In addition, close examination of the ends of the beam also revealed the lower flange

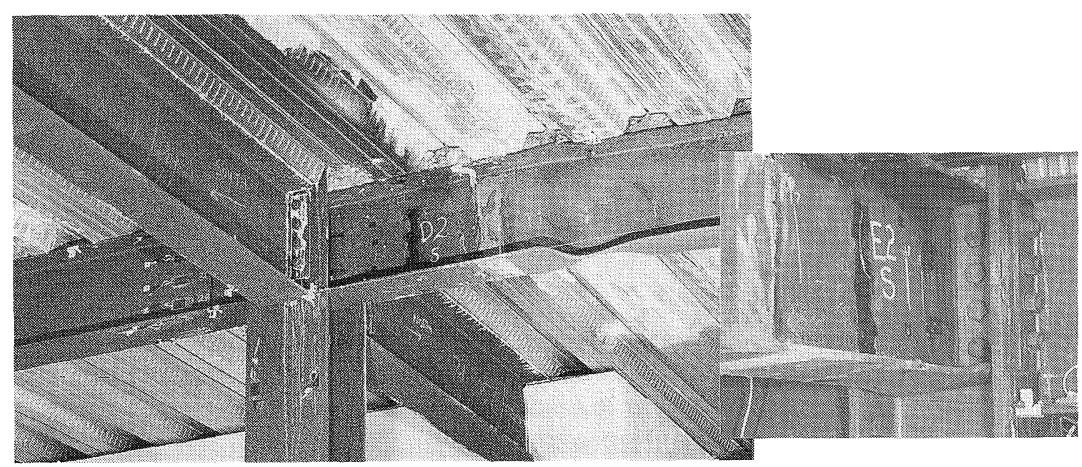

FIGURE 6. LOCAL BUCKLING AND DEFORMATION AT THE END OF THE BEAM 


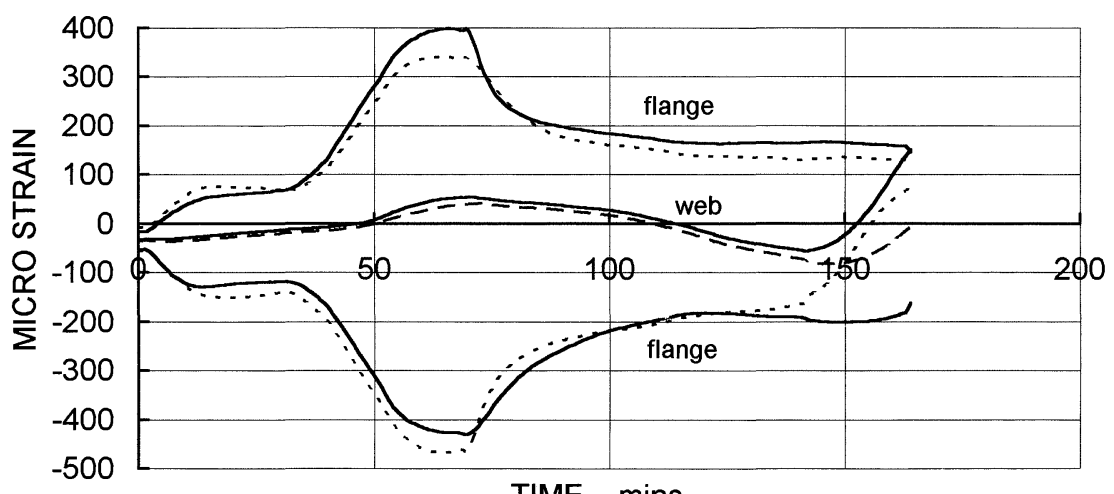

TIME, mins.

FIGURE 7. STRAIN PROFILE IN THE COLUMN ADJACENT TO THE CONNECTION

had distorted, inset Figure 6, as it expanded against the web of the column section. The occurrence of these effects can be identified from abrupt changes in the strain profiles around the connections, Figure 7 , as well as by other measurements such as beam rotation and lateral displacements of the lower flange.

Clearly, in a partial depth end plate, the gap between the end of the lower flange in the beam and the column web is controlled by the thickness of the plate and therefore will determine at what temperature it closes through a combination of rotation and thermal expansion. This interaction between the beam and column with the composite slab, will affect the stiffness at the connection, local buckling of the beam and ultimately the overall performance of the floor system. If therefore, the behaviour observed in this test is to be used to predict the performance of other frames in which the composite floor system, beam size, depth and thickness of end plate may be different, then a thorough understanding of the structural changes is essential to developing numerical analysis procedures that describe these effects.

\section{D - Plane Frame}

The second test was designed to evaluate the behaviour of a series of beams and columns supporting the fourth floor across the full width of the building, Figure 8.

One of the objectives of the test was to examine the behaviour of the frame around the connections and the type of deformation observed in the Broadgate fire in London a few years ago which resulted in buckling at the column heads. It was also necessary to determine how important fire protection should be extended around the type of connection used in the BRE frame when the column themselves are insulated. For these reasons, all the columns were lightly protected to a height of $200 \mathrm{~mm}$ below the connections. The beams as well as the beam/beam and beam/column connections remained totally exposed. 


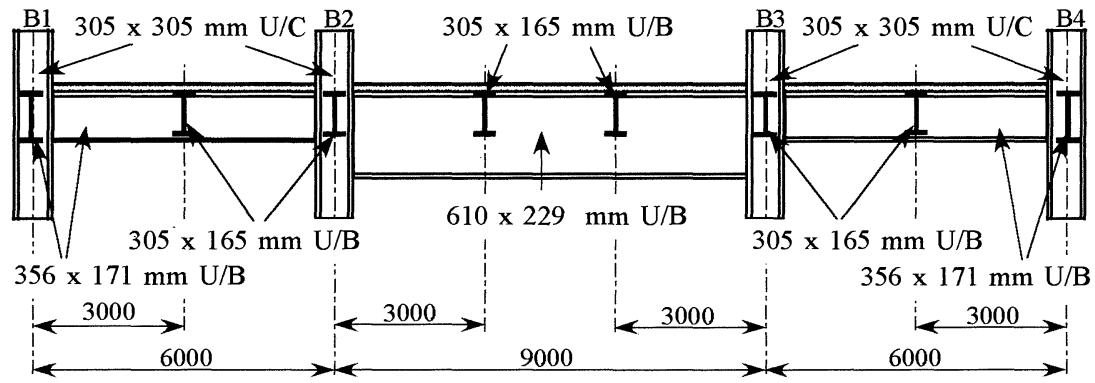

\section{FIGURE 8. SCHEMATIC REPRESENTATION OF THE PLANE FRAME TEST}

Using concrete blockwork, a gas fired furnace $21 \mathrm{~m}$ long $\mathrm{x} 4 \mathrm{~m}$ high was built to form a corridor across the full width of the building. Slots were built into the walls to allow the secondary beams to deflect unimpeded and for instrumentation bars to transmit movement of the internal structure to externally placed transducers. Heating was provided by eight industrial burners mounted on one side of the furnace near floor level. The test arrangement was over four times longer than the Standard fire resistance furnace, Figure 9.

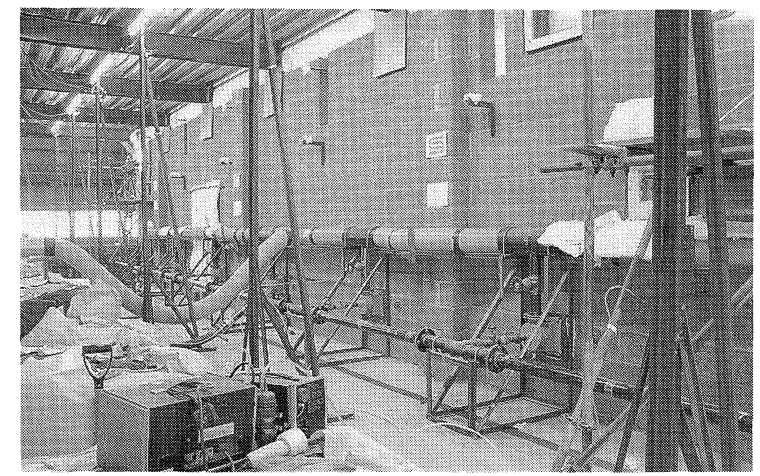

FIGURE 9. PART OF THE PLANE FRAME TEST FURNACE

The structure was heated over a period of $21 / 2$ hours during which the beams attained temperatures of around $800^{\circ} \mathrm{C}$ in the lower flange with a maximum of $850^{\circ} \mathrm{C}$ being recorded. The main $610 \mathrm{~mm}$ deep primary beam deflected $293 \mathrm{~mm}(\mathrm{~L} / 31)$ and recovered to $237 \mathrm{~mm}$ once the structure cooled back to ambient temperature.

Temperatures in the exposed portions of the internal columns just below the connections, attained $700{ }^{\circ} \mathrm{C}$ and while they were still straight over the majority of their length, the column 


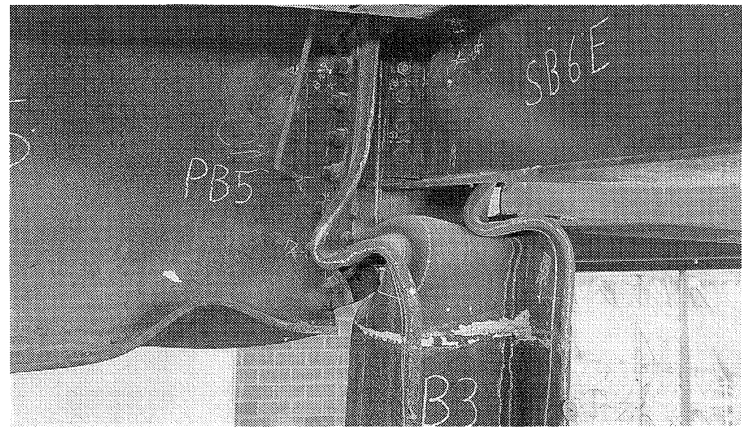

\section{FIGURE 10. DETAIL OF AN INTERNAL BEAM TO COLUMN CONNECTION}

heads and connections had grossly distorted and in effect had been squashed the $200 \mathrm{~mm}$ clearance at the top of the fire protection, Figure 10. In contrast, the columns at either end of the frame remained relatively undistorted.

While the extent of deformation observed in the column was well beyond the normal acceptable limits of a Standard fire test, the structural stability of the frame was maintained by developing alternative load paths. This is illustrated in Figure 11 by the strain profile measured across an internal column within the furnace. Towards the end of the test, complete strain reversal occurred and even allowing for the induced strains existing in the structure before the test commenced, this particular member was now acting in tension.

Apart from being able to mimic the behaviour of the structure observed in the Broadgate fire, two further important aspects emerged from this test:

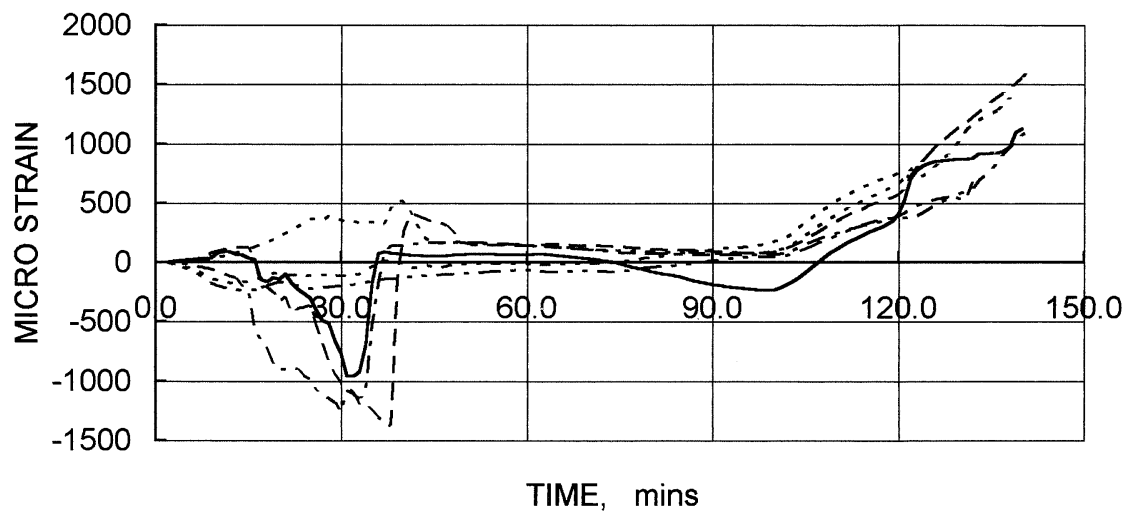

FIGURE 11. STRAIN PROFILE ACROSS AN INTERNAL COLUMN. 
a) Local 'squash' buckling experienced at the top of the column did not occur until temperatures exceeded those expected after 30 minutes of heating in a Standard test.

b) Lateral displacements of the edge columns due to thermal expansion of the beams across the full width of the structure $(21 \mathrm{~m})$, were only $25 \mathrm{~mm}$.

\section{D - Corner Test}

The objective of the third test was to evaluate the membrane action developed in a composite steel deck floor system. However, since it was necessary to create a 'natural' fire to achieve the required thermal input into the structure, the opportunity was also used to provide additional information in the validation of Eurocode 1: Part 2.2 'Actions on Fire' (1).

A compartment with a floor area of approximately $80 \mathrm{~m}^{2}$ was built on the first floor in one corner of the structure. To ensure that the gable end wall did not contribute to supporting the loads, all the restraints and ties including the wind posts were removed. Ventilation was provided by a single $7 \mathrm{~m}$ wide opening partially covered by an adjustable screen and although the initial ventilation conditions required were pre-calculated, the screen enabled some control to be maintained over the burning rates and the temperatures attained within the compartment. Based upon the behaviour of the frame in the second test, the columns and perimeter beams including the main connections, were protected with $25 \mathrm{~mm}$ ceramic fibre blanket. However, the internal primary and secondary beams including the fin plate connections, remained totally exposed.

To test the structure, it was necessary to develop temperatures of around $1000^{\circ} \mathrm{C}$. From calculations based upon the parametric equations given in Eurocode 1, this was achieved with a fire loading of $45 \mathrm{~kg}$ of wood $/ \mathrm{m}^{2}$ of floor area with only a small adjustment made to the initial ventilation conditions during the test. Figure 12 compares the measured atmosphere temperatures in the compartment with the calculated parametric time temperature curves for the two ventilation conditions adopted.

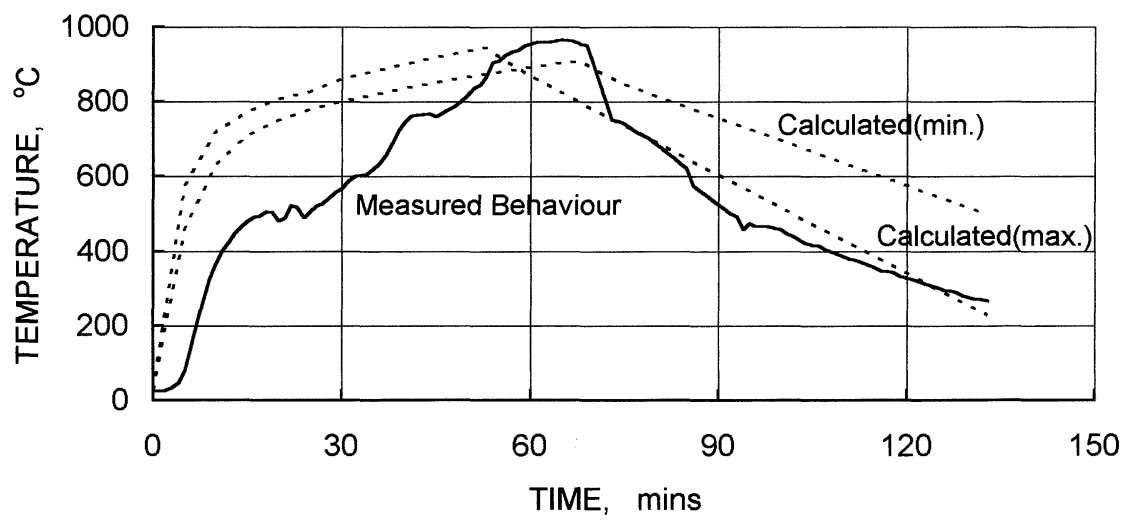

FIGURE 12. CALCULATED AND MEASURED COMPARTMENT TEMPERATURES 
Steel sections protected with Vicuclad were included in the test to measure the severity of the fire in terms of the ISO834 test. The temperatures attained were found to be equivalent to a heating period of 85 minutes which compares favourably with 94 minutes calculated using EC1 and 89 minutes using the Pettersson formula ${ }^{(2)}$. Weighing platforms were also used to measure crib weight loss and for the burning period from $80-30 \%$ of the fire loading, the heat output averaged 19MW.

In the fire, the unprotected beams were heated to between $860-1020^{\circ} \mathrm{C}$. At these temperatures structural steel has less than $10 \%$ of its ambient temperature strength, yet despite this weakness, 'failure' did not occur and neither had the primary and secondary beams attained instability. This behaviour clearly demonstrates the important role a composite slab provides in maintaining structural integrity of the floor.

\section{Office Fire (Demonstration)}

The purpose of the fourth test in the programme was to demonstrate some of the important conclusions reached in the earlier studies in a more realistic fire scenario at the same time evaluating other aspects of structural behaviour not previously addressed.

A compartment up to $18 \mathrm{~m}$ wide and $10 \mathrm{~m}$ deep was built on the first floor of the building to represent an open plan office. This was fitted out as a series of work stations using modern day furnishings, computers and filing systems, Figure 13.

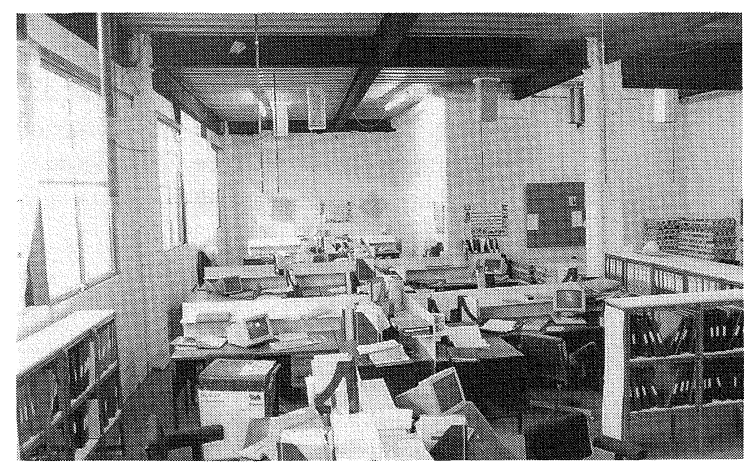

\section{FIGURE 13. LAYOUT OF THE OFFICE FIRE COMPARTMENT}

Although it was possible to identify a wide range of scenarios with variables such as; fire loading, ventilation, method of ignition and fire spread, the test conditions were designed to create a severe fire that would 'test' the structure. For example:

* The total fire loading was equivalent to $46 \mathrm{~kg}$ of wood $/ \mathrm{m}^{2}$ of floor area of which $19 \%$ was made up of plastic materials. This quantity of combustible material is in excess of 
the $95 \%$ fractile for office fire loadings (the $80 \%$ fractile is currently proposed in the UK draft design codes).

* The location of the fire source, ignition sequence and initial ventilation conditions were designed to assist fire growth and increase the likelihood of flashover.

* The ventilation area was also calculated to develop high temperatures in the compartment but not to be over ventilated for the fire to burn out before the structure had time to respond. Once flashover occurred the fire was ventilation controlled with a maximum heat release rate of 58MW, Figure 14 .

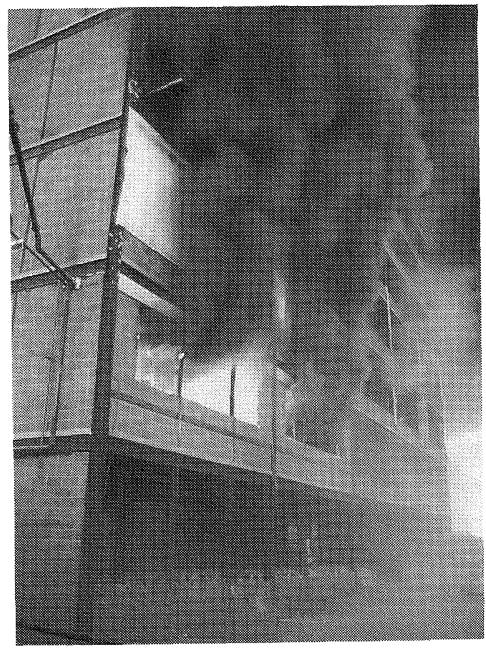

FIGURE 14. OFFICE FIRE IN PROGRESS

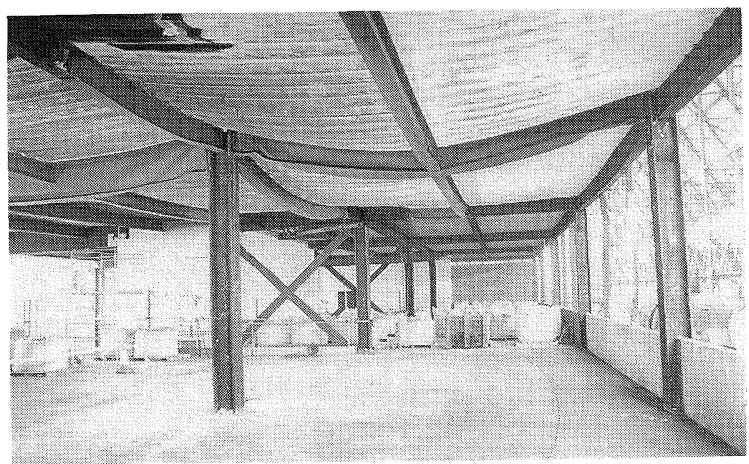

FIGURE 15. STRUCTURAL FRAME AFTER THE OFFICE FIRE 
As in the third test the columns and the main beam to column connections were protected. However, all the beams including the beam to beam connections remained fully exposed. The wind posts and gable wall restraints also remained unprotected.

The fire was started in one corner of the compartment and within 10 minutes local atmosphere temperatures had attained $900^{\circ} \mathrm{C}$. Maximum atmosphere and steel temperatures of $1150^{\circ} \mathrm{C}$ and $1100^{\circ} \mathrm{C}$ were eventually recorded. All the combustible material was completely burnt including the contents of filing cabinets. Figure 15 shows the internal structure once the floor had been cleared. Although large deflections were measured, the frame was structurally stable and still carried the loads after the fire. However as a result of this deformation the integrity of the floor slab around the internal column had suffered and it was also evident that during cooling, very high tensile stresses developed at the connections due to thermal contraction of the deflected beams.

\section{CONCLUDING REMARKS}

Although analysis of the data and formulation of numerical procedures are currently being developed the tests have already confirmed important aspects of structural behaviour and identified issues which need to be addressed on fire safety:

a) Unprotected beams attained extremely high temperatures, often in excess of $1000^{\circ} \mathrm{C}$. At this level of heating the strength of steel has only around 5\% of its ambient temperature strength. Since their structural contribution at the fire limit state was small, protection of all of these members is questionable.

b) The tests identified columns as the most critical elements and while alternative load paths can be utilised, local buckling of these members have severe disproportionate consequences in other parts of the structure not directly involved in the fire.

c) The importance of membrane action has been clearly demonstrated in providing stability to the composite floor. However, the ductility of the steel mesh reinforcement and alternative design solutions in its positioning around columns to maintain slab continuity and integrity, need to be examined.

d) Thermal expansion of the steel has often been associated with pushing out walls. In the tests conducted lateral displacements of the columns were minimal.

e) Large deflections were experienced in the floor slab and in the majority did not exceed the current limitations prescribed in the Standard test. However in real structures, these may exceed the tolerable limits of vertical separating elements. Careful consideration needs to be given to both the design and positioning of compartmentation systems.

\section{REFERENCES}

1. Eurocode 1: Basis of Design and Actions on Structures, Part 2.2: Actions on Structures Exposed to Fire, ENV 1991-2-2, 1994.

2. Pettersson, O., "Structural Fire Protection, Report of Group Session 5.2, CIB W14 Meeting, Copenhagen", Fire and Materials, 4, 1-16, 1980. 